\section{Kim Williams*}

* Corresponding author

Kim Williams Books Corso Regina Margherita, 72 10153 Turin (Torino) ITALY kwb@kimwilliamsbooks.com

\section{Michela Rossi}

\author{
Department of Industrial \\ Design, Art, Comunication and \\ Fashion (INDACO) \\ Politecnico di Milano \\ Milan, ITALY \\ michela.rossi@polimi.it
}

Keywords: Nexus conference, architecture and mathematics
Conference Report

\section{Nexus 2012: Relationships Between Architecture and Mathematics}

\begin{abstract}
The ninth edition of the biennial conference series "Nexus: Relationships Between Architecture and Mathematics" took place at the Politecnico di Milan in June 2012. There are many connections between architecture and mathematics: mathematic principles may be used as a basis for an architectural design, or as a tool for analyzing an existing monument; architecture may be a concrete expression of mathematical ideas, becoming, in a sense, "visual mathematics". The purpose of the Nexus conference series is to bring together all those working with ideas related to both architecture and mathematics, and to allow researchers to exchange ideas first-hand. Papers presented at the conference are published in the Nexus Network Journal, providing a permanent archive of studies in architecture and mathematics, and in 2012 a special volume of papers from the Ph.D. Day and the poster session was published.
\end{abstract}

The ninth international, interdisciplinary Nexus conference for architecture and mathematics, "Nexus 2012: Relationships Between Architecture and Mathematics", took place 11-14 June 2012, in Milan, Italy. This edition of our research community's biennial meetings was jointly sponsored by the Department of Industrial Design, Art, Communication and Fashion (INDACO) and the Department of Mathematics "Francesco Brioschi" of the Politecnico di Milano. It was a meeting full of "firsts": the first time we have had speakers from China and Russia; the first time we have had participants from Iran; the first time - thanks to the idea of this year's co-director, Michela Rossi - that we have had a day especially dedicated to the work of those who are either currently working on their Ph.D. dissertations or have received their Ph.D. within the last two years; the first time we have had a whole session dedicated to another discipline - archaeoastronomy, moderated by Giulio Magli - allowing us to exchange ideas and methodologies with scholars in a field whose research aims are very close to our own.

To put the 2012 meeting into context, let's look at some past statistics of Nexus meetings. The first conference, "Nexus '96" had a total of 23 participants, with 13 speakers from 6 countries. Germany, Hungary, Italy, Switzerland, UK, USA. Nexus 2012 had a total of 100 participants total, with 21 presentations and 4 keynote speakers from 5 continents (Europe, North America, South America, Asia, Australia). The countries represented were Australia, Canada, Chile, Denmark, China, France, Germany, Italy, Portugal, New Zealand, Russia, Saudi Arabia, Spain, Turkey, USA.

Speakers for this year's meeting were chosen by members of the scientific committee, made up of Kim Williams (founder of Nexus and editor-in-chief of the Nexus Network Journal), Michela Rossi (INDACO, Politecnico di Milano), Franca Caliò, Elena Marchetti and Giulio Magli (Dipartimento di Matematica, Politecnico di Milano), Sylvie Duvernoy (Department of Architecture, University of Ferrara), Rossella Salerno (Department of Architecture and Planning, Politecnico di Milano) and Vasco Zara 
(Université de Bourgogne). The scientific committee first evaluated the group of 144 abstracts received from those who answered the Call for Papers issued in late 2010 to determine who to invite to submit full papers for the final selection. The 21 presenters were then chosen from the restricted group of 40 full papers submitted.

The logo for Nexus 2012 was also chosen by competition. The announcement for the competition stated the following criteria:

The logo should capture the "nexus" of architecture and mathematics, the interdisciplinary subject of the Nexus conferences. References to the conference venue in the city of Milan are also appreciated. Designers should remember that the logo design should be meaningful at a variety of scales, from full-size to thumbnail.

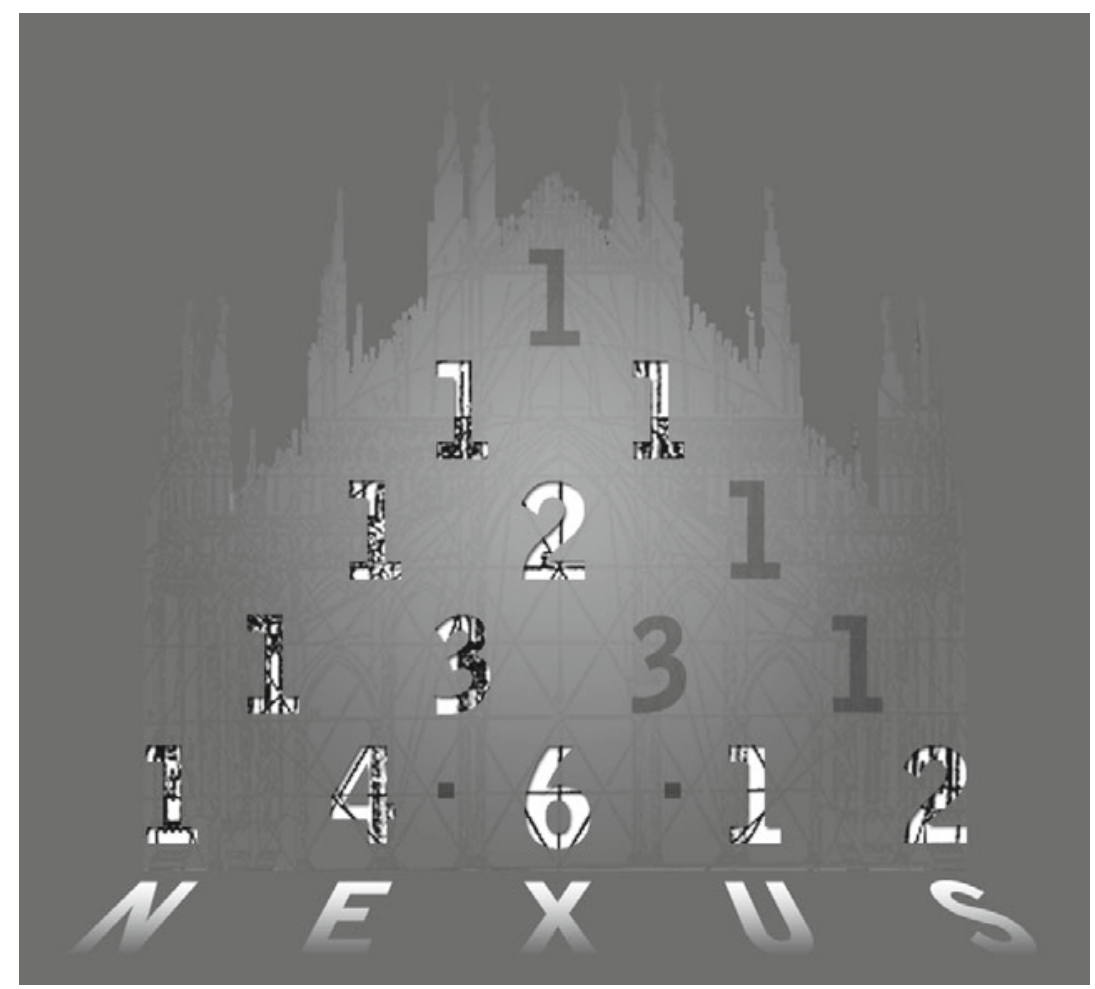

One winner and one honourable mention were chosen from among the twenty entries. The winning logo was designed by Ivan Mechkunov. He described it this way:

The Logo design contains an architectural object, a mathematical object and a relation between the two. It also contains information about "What", "Where" and "When" incorporated into the graphic part rather than in a separate text.

The Milan Cathedral was chosen to represent the architectural object for several obvious reasons:

- Being one of the symbols of Milan it signifies the place of the conference. 
- As a recognizable Gothic building it exemplifies the use of mathematics in both the tectonics and the proportions of Gothic architecture and architecture in general.

- The Cathedral was analyzed by the Milanese Architect and Geometer Cesare Cesariano in the early 16th Century - "apparently the first precisely measured illustrations of Gothic architecture in a printed book".

The Pascal Triangle was selected for the following reasons:

- It is a constructed object as architectural objects are.

- It exhibits interesting mathematical properties.

- Its visual shape relates to one of the basic elements in the Cesare Cesariano's analysis - the Triangle.

- It hides the Fibonacci series and, therefore, the Golden Ratio, the same way buildings hide invisible relations.

- It contains, with a slight modification, the dates of the conference.

Can the reader spot the conference dates within the logo?

The honourable mention was awarded to Aineias Oikonomou for his design, which also featured the Milan Cathedral. All the entries can be seen on the website of the NNJ, at: http://www.nexusjournal.com/logo.html.

The 2012 four-day meeting comprised six lecture sessions, each devoted a specific theme. The morning session of Monday 11 June was entitled "Design from Antiquity to the Future" and was moderated by Kim Williams. The talks all concerned the kind design issues that architects of all epochs have faced: how to organize and optimize their designs. Here four different mathematical tools were considered: grids, geometry, fractals and topology. The speakers were Michael Ytterberg, "The Dance in the Labyrinth: The Hidden Order of Hadrian's Villa and the Order of Modern Architecture"; Benjamin Ibarra-Sevilla, "The Hidden Face of the Vault: Unveiling the Expression of the AvantGarde through the Use of the Sphere in Teposolula's Open Chapel"; Jiang Liang presented the research she carried out with Yan-qui $\mathrm{Hu}$ and Hui San, "The Design Evaluation of Green Space Elements of Urban Squares Based on Fractal Theory". Silvia Benvenuti, Fabio Ceccanti and Xavier De Kestelier took us into outer space with "Living on the Moon: Topological Optimization of a 3D-Printed Lunar Shelter". As an extra, mathematician Alexander Hahn made a short presentation of his book, Mathematical Excursions to the World's Great Buildings (Princeton University Press, 2012).

The Monday afternoon session was divided into two parts. The first, moderated by Vasco Zara, focused on "Music, architecture and mathematics". Proportional relationships are a common denominator of architecture and music. The two presentations in this session showed that interest in that affinity has spanned the ages. The speakers were Radoslav Zuk, "Three Musical Interpretations of Le Corbusier's Modulor", and Michela Costantini, "Signs of the Eighteenth-Century Debate on the Harmonic Theory in Piedmont". Moderator Vasco Zara of the Université de Bourgogne, who presented a paper entitled "From Quantitative to Qualitative Architecture in the Sixteenth and Seventeenth Centuries: A New Musical Perspective" at Nexus 2010 in Porto (see NNJ vol. 13, no. 2 (Autumn 2011), pp. 411-430) made a short presentation about meeting planned in 2013 on music and architecture in Daniele Barbaro's sixteenth-century translation and commentary of Vitruvius. The second part of 
the session was devoted to "Design and Representation Analysis", with Sylvie Duvernoy as moderator. The idea was to examine graphic techniques of analysis. Michael Ostwald presented "Differentiating Between Line and Point Maps Using Spatial Experience: Richard Neutra's Lovell House", a research project carried out with Michael Dawes. Eliana Manuel Pinho and João Pedro Xavier presented "Grid-Based Design in Roman Villas: A Method of Analysis”. Finally, Branko Mitrović presented “Nelson Goodman's Arguments against Perspective", arguments which had been based on faulty reasoning about the geometry of light rays and perspective.

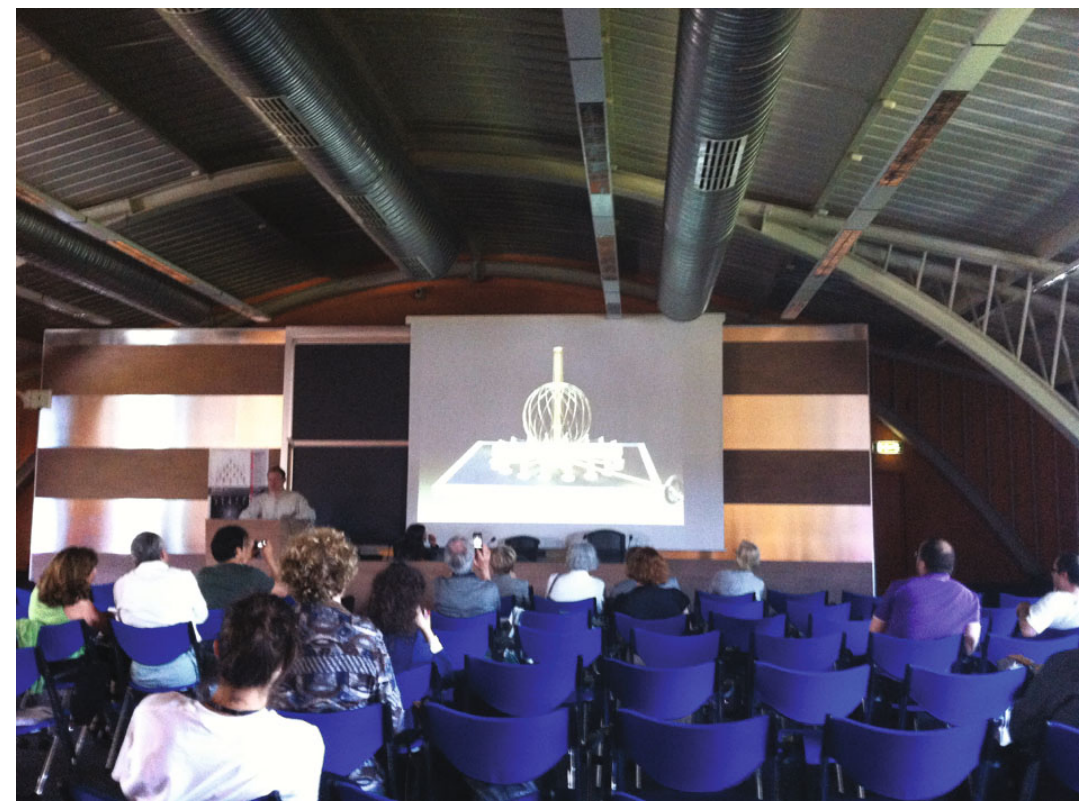

A typical moment from the Nexus 2012 conference

Monday closed with the first of three keynote lectures. The speakers were Fulvio Irace, an architectural historian at the Politecnico di Milano, and Anna Chiara Cimoli, an independent scholar, co-authors of a book entitled Divina Proporzione. They presented "Triennale 1951: Post-War Reconstruction and 'Divina Proportione", about the landmark post-war meeting that brought together the leading lights of that epoch's world of design: Le Corbusier, Rudolf Wittkower, Bruno Zevi, Pier Luigi Nervi, Max Bill, James Ackerman, and others. At a moment when Europe was struggling to rebuild and shape a new society following the devastation of World War II, the topic hotly debated at that historic conference was what system of proportion, if any, should be used by architects. This was an exciting presentation for several reasons. First, in many respects it was similar in theme and aims to our own Nexus conference, making it a kind of predecessor for our work today. Second, taking part in the 1951 meeting was the Swiss mathematician Andreas Speiser, who was the uncle of physicist David Speiser, who was a very active participant in the first four Nexus conferences (Fucecchio, Mantua, Ferrara and Óbidos).

The Tuesday morning session was dedicated to "Parametric Design" and was moderated by Michela Rossi. While the talks given on Monday considered topics that have been discussed since the very first Nexus conference in 1996, parametric design 
represents one of the new directions of investigation in architectural theory. Arzu Gönenç Sorguç, from Turkey, presented a work carried out with Semra Arslan Selcuk entitled "Computational Models in Architecture: Understanding Multi-Dimensionality and Mapping". Rodrigo Garcia Alvarado from Chile discussed "Parametric Development of Variable Roof Structures with Central Supports (Tulips)". In "Precise Experiments: Relations between Mathematics, Philosophy and Design at Ulm School of Design", Cornelie Leopold from Germany looked back at what kind of parameters were being considered when Max Bill was running the Ulm School of Design.

The Tuesday afternoon session was devoted to a round table discussion focusing on didactics, entitled "Descriptive Geometry and/or Computer Technology? What mathematics for doing and understanding architecture?", moderated by Ivan Tafteberg Jakobsen and Jesper Matthiasen, who are members of the Nexus Network Journal editorial board specializing in matters of education. The participants in the round table were Cornelie Leopold (Germany), Michael Ostwald (Australia), João Pedro Xavier (Portugal), Sylvie Duvernoy (Italy), Arzu Gönenç Sorguç (Turkey), Federico Fallavollita (Italy), who compared and contrasted the type of mathematics taught to architecture students in their home countries.

Concluding the afternoon session was the projection of two short videos. The first, presented by Alberto Sdegno, was entitled "On the origin of computer graphics: Short videos from the 60s" and showed the genesis of today's computer representations in architecture. The second, presented by João Pedro Xavier, was about the 2003 project to study Leonardo da Vinci's reciprocal structures, a project to be taken up again in 2013 with a workshop in Portugal. João Pedro also made a short presentation of the poster session that was to follow.

Tuesday's keynote lecture was given by Helmut Pottmann, Director of the Geometric Modeling and Scientific Visualization Research Center and Professor of Applied Mathematics and Computational Science in the Mathematical and Computer Sciences and Engineering Division at King Abdullah University of Science and Technology, Saudi Arabia. In a talk entitled "Geometric Computing for Freeform Architecture", he presented some of the very exciting architectural possibilities made possible by geometry and computer science today.

The day continued with the "Nexus 2012 White Night", beginning with a "Poster Party", a fun aperitif and light supper held in the space where posters were displayed, giving participants a chance to mingle and chat while looking at posters and exchanging ideas with their makers. After dinner participants returned to the lecture hall to listen to the evening talk by mathematician Alfio Quarteroni, who divides his time between the Politecnico di Milano and the École Polytechnique Federale de Lausanne, Switzerland. His very engaging lecture was entitled "Mathematical models for simulation and optimal design".

The morning session of Wednesday 13 June was entitled "Archaeoastronomy, architecture and mathematics" and was moderated by Giulio Magli. Michael A. Rappenglück presented "The Housing of the World: About the Significance of Cosmographic Concepts for Habitation”. Marina De Franceschini and Giuseppe Veneziano presented "Architecture and Archaeoastronomy in Hadrian's Villa near Tivoli, Rome", making an interesting alternative reading to the interpretation of Hadrian's Villa presented on Monday by Michael Ytterberg. Javier Mejuto presented "Astronomical Architecture and Landscape Modification in Prehistoric Iberian Peninsula”. Manuela 
Incerti discussed "Astronomical Knowledge in the Sacred Architecture of the Middle Ages in Italy".

The afternoon of Wednesday was devoted to "Mathematics in architectural surfaces", divided into two parts, the first moderated by Franca Caliò, the second by Elena Marchetti. The investigation of surfaces is one of the most avant-garde areas in architectural research, as the talks by Helmut Pottmann and Alfio Quarteroni showed. Michele Emmer presented "Minimal Surfaces and Architecture: New Forms". The research group of Andrea Casale, Graziano Mario Valenti, Michele Calvano and Jessica Romor presented "Surfaces: Concept, Design, Parametric Modeling and Prototyping. Dmitri Kozlov discussed "Structures of Periodical Knots and Links as Geometric models of Complex Surfaces for Designing”. Nicole Blanc and Bernard Parzysz discussed an ancient surface in "A Puzzling Set of Stucco Ceiling Coffers from Portici: Archaeology and Mathematics Working Together".

To close the day's activities, Giulio Magli gave a short presentation on "Architecture and Astronomy in the Age of the Pyramids". He then introduced the afternoon's keynote lecturer, Robert Hannah, whose talk was entitled "Greek Temple Orientation: The Case of the Older Parthenon in Athens".

The fourth day of the conference was the Nexus 2012 Ph.D. day, especially dedicated to the work of those who are either currently working on their Ph.D. dissertations or have received their Ph.D. within the last two years. Like the abstracts and papers of the speakers in the conference, the papers accepted for the Ph.D. day were double-blind peer reviewed by members of a scientific committee composed of Marco Gaiani (University of Bologna), Cornelie Leopold (TU Kaiserslautern), Edie Miglio (Politecnico di Milano), Branko Mitrović (UNITEC Auckland), Francesco Trabucco (Politecnico di Milano), João Pedro Xavier (FAUP Porto) and Maria Zack (Point Loma Nazarene University, San Diego). This gave students a chance to present their doctoral research projects and benefit from the criticisms of the professors who were present, as well as exchange ideas and information with Ph.D. students from other countries and programs. It was an important step forward because these students represent the future of advanced studies in architecture and mathematics.

As is by now customary, the papers presented at the conference will be published in the Nexus Network Journal over the course of the three issues of the coming year. The presentations from the Ph.D. Day, together with posters displayed at this year's meeting, were collected and published in a special book. Entitled Nexus Ph.D. Day. Relationships between Architecture and Mathematics, it was edited by Michela Rossi (McGraw-Hill, ISBN 978-88-386-7333-7). It can be ordered online from the Italian site of McGrawHill:

http://www.catalogo.mcgraw-hill.it/catLibro.asp?item_id=2847

\section{About the authors}

Kim Williams is the director of the conference series "Nexus: Relationships Between Architecture and Mathematics" and the founder of the Nexus Network Journal.

Michela Rossi received her degree in architecture at the University of Florence and her Ph.D in architectural survey and representation at the University of Palermo in 1993. She is associate professor at the Politecnico di Milano, where she teaches drawing in design courses. Her research interests center on relationships between drawing, geometry and architecture. She was co-director of Nexus 2012 in Milan. 